\title{
Retraction Note to: Menière's disease: combined pharmacotherapy with betahistine and the MAO-B inhibitor selegiline-an observational study
}

\author{
Michael Strupp ${ }^{1}$ (D $\cdot$ Ludwig Kraus $^{1} \cdot$ Franz Schautzer $^{2} \cdot$ Dan Rujescu $^{1,3}$
}

Published online: 18 March 2020

๑) Springer-Verlag GmbH Germany, part of Springer Nature 2020

\section{Retraction Note to: Journal of Neurology (2018) 265 (Suppl 1):S80-S85 https://doi.org/10.1007/s00415-018-8809-8}

The authors have retracted this article [1] because it erroneously gives the impression that the results presented were based on a clinical trial, when in fact the patients treated in this observational study underwent so-called "individuelle Heilversuche" (individual patient treatment). "Individuelle Heilversuche" is a type of medical treatment that deviates from the established medical standard. The healing attempt is aimed primarily at curing a specific patient, rather than conducting experimental research. Therefore, these individual healing attempts cannot be referred to as a clinical study. All authors agree with this retraction.

\section{Reference}

1. Strupp M, Kraus L, Schautzer F, Rujescu D (2018) Menière's disease: combined pharmacotherapy with betahistine and the MAO-B inhibitor selegiline-an observational study. J Neurol 265:s80-s85.https://doi.org/10.1007/s00415-018-8809-8
The original article can be found online at https://doi.org/10.1007/ s00415-018-8809-8.

Michael Strupp

Michael.Strupp@med.uni-muenchen.de

1 Department of Neurology and German Center for Vertigo and Balance Disorders (DSGZ), Ludwig Maximilians University, Munich, Campus Grosshadern, Marchioninistr. 15, 81377 Munich, Germany

2 Department of Neurology, Landeskrankenhaus Villach, Villach, Austria

3 Department of Psychiatry, University Hospital Halle, Halle, Germany 